\title{
Silent brain infarcts in chronic kidney disease patients with nonspecific neurological symptoms
}

\author{
Sasanka P. ${ }^{1 *}$, Chandra T. ${ }^{2}$ \\ DOI: https://doi.org/10.17511/ijmrr.2021.i04.11 \\ 1* P Sasanka, Assistant Professor, Department of Nephrology, GSL Medical College, Rajahmundry, Andhra Prades, India. \\ 2 T Jaya Chandra, Professor, Department of Microbiology, GSL Medical College, Rajahmundry, Andhra Pradesh, India.
}

Introduction: Silent brain infarcts (SBI) are parenchymal lesions of previous infarcts, classified as type III cerebrovascular disorder. A study was undertaken to find the relation between SBIs and nonspecific neurological complaints, an association of high sensitivity C-reactive protein (hsCRP) with silent brain infarcts. Methodology: It was a cross-sectional study conducted in the department of Nephrology, GSL Medical College, from January to December 2020. Individuals aged $\geq 18$ years with nonspecific neurological complaints were included. MRI brain, hSCRP and electrocardiogram were also carried as per the standard protocol. Fischer exact test was used to find the statistical significance; $P<0.05$ was considered statistically significant. Results: A total of 51 members have included the male-female ratio was 1.04. SBI was presented in $27.4 \%$ (14). Age-wise, among the cortical SBI patients, maximum (75\%) were in the $\geq 61$ years group. High density lipoprotein levels were $>40 \mathrm{mg} / \mathrm{dL}$ in $39.2 \%$, normal triglycerides (TGL) were observed in $71 \%$ and raised hsCRP in $62.7 \%$ (32). Statistically, there was no significant difference in TGL levels. hsCRP levels were raised in $3(75 \%)$ members with cortical SBI; statistically, there was no significant difference. Conclusion: The traditional risk factors associated with stroke were present in the patients with SBI. hSCRP was raised in chronic kidney disease patients having NSCL and having SBI.

Keywords: Study, Participant, Levels

Corresponding Author

P Sasanka, Assistant Professor, Department of Nephrology, GSL Medical College, Rajahmundry, Andhra Prades, India.

Email: sasankap1982@gmail.com
How to Cite this Article

To Browse

P Sasanka, T Jaya Chandra. Silent brain infarcts in chronic kidney disease patients with nonspecific neurological symptoms. Int J Med Res Rev. 2021;9(4):274-279.

Available From

https://ijmrr.medresearch.in/index.php/ijmrr/article/ view/1320

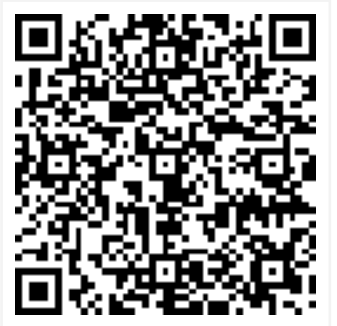

Manuscript Received 2021-07-16

Conflict of Interest No

(c) 2021 by P Sasanka, T Jaya Chandra and Published by Siddharth Health Research and Social Welfare Society. This is an Open Access article licensed under a Creative Commons Attribution 4.0 International License https://creativecommons.org/licenses/by/4.0/ unported [CC BY 4.0].

Accepted 2021-08-31 2021-07-28 2021-07-28

view Round 2 2021-08-10

Riew Round 3

Note 


\section{Introduction}

Silent brain infarcts (SBI) are parenchymal lesions of previous infarcts that have not been associated in that individual with clinical signs or symptoms of a stroke. [1]. It is now classified as a type III cerebrovascular disorder by the National Institute of Neurological Disorders and stroke, a powerful predictor of clinical stroke. [2]. It is considered a preclinical warning of symptomatic strokes and brain damage related to multiple deep infarcts. To prevent these further disabling diseases, it is essential to characterise and manage this preclinical stage of cerebrovascular disease. [3].

Up to half of the patients with vascular risk factors harbour SBI's on MRI, and this percentage is as high as $57 \%$ in old patients. [4]. Silent lacunar strokes occur in one-third of people aged $>65$, and the risk is more than double for the development of dementia, particularly when present in the thalamus. [5]. Inflammatory processes are involved; C-reactive protein (CRP) is a sensitive marker of low-grade systemic inflammation. [6].

Histopathological findings showed that CRP has direct prothrombotic and proatherosclerotic effects, primarily related to executive function, the cognitive function most vulnerable to vascular disease. [7]. A study demonstrated an association of CRP with cerebral small vessel disease as measured by white matter hyperintensities (WMH) and the presence of silent brain infarcts. [6]. Higher plasma levels of CRP and IL- 6 were associated with an increased risk of SBI. [8].

Patients with SBIs showed decreased cerebral blood flow (CBF) and metabolic rate for oxygen in the deep grey matter; on the other hand, decreased CBF with milder Increased Oxygen extraction fraction (OEF) resulting in pursued CMRO in the cerebral cortex, which indicates the presence of occult misery perfusion; suggesting that patients with SBI have reduced cerebral perfusional reserves. [9]. SBIs are more prevalent than symptomatic infarcts and may increase the actual public health burden of stroke [10]. hypertriglyceridaemia and large waist circumference are the significant risk factors. [11].

Because of the above, the present study was undertaken to find the relation between SBIs and nonspecific neurological complaints, an association of high sensitivity C-reactive protein (hsCRP) with silent brain infarcts.

\section{Materials and Methods}

Settings: The study was conducted in the department of Nephrology, GSL Medical College, Rajahmundry.

Duration and type of study: This was crosssectional research. This was conducted over 12 months, from January 2020 to December 2020.

Sampling method: Random sampling was considered in this study.

Sample size calculation: All the eligible members who satisfy the inclusion criteria were considered in this study.

Inclusion criteria: Individuals aged $\geq 18$ years, with nonspecific neurological complaints like headache, vertigo, dizziness, tinnitus, syncope and chronic kidney disease (CKD) who attended outpatient department and inpatient department and are asymptomatic at the time of examination were included in this study.

Exclusion criteria: Individuals with an old cerebrovascular accident, stroke, infections, claustrophobia, valvular prosthesis, vascular clips, cardiac pacemakers, cochlear implants, other implanted devices sensitive to strong magnetic fields and those who were non-cooperative were excluded.

Data collection, procedure: The study members were enquired about nonspecific neurological complaints, the previous history of significant risk factors and pre-existing diseases such as diabetes mellitus, hypertension, ischaemic heart disease, smoking, alcohol consumption, recent onset of any Infections were asked; detailed general and neurological examination were done. Height and weight were recorded on the study proforma. Body mass index for obesity was calculated by measuring height and weight in light clothes and without shoes. All routine investigations such as hemoglobin, total leukocyte count, differential count and erythrocyte sedimentation rate (ESR), routine urine examination, urine microscopy, fasting blood sugar, and lipid profile were analysed. MRI brain, hsCRP and electrocardiogram were also carried as per the standard protocol.

MRI was evaluated with 1.5 Telsa Siemens symphony. T-2 weighted double spine echo coronal weighted sequences were acquired in $3-5 \mathrm{~mm}$ contagious slices from nasion to occiput with a 
Repetition time of 4500 milliseconds and echo time of 116 milliseconds.

Only lesions larger than $3 \mathrm{~mm}$ were considered as SBI. Lesions were also required to have a cerebrospinal fluid density on subtraction images and to be distinctly separate from the circle of Willi's vessels for suspected basal ganglion infarcts, Investigators blinded to subject demographic and stroke risk factor data processed and analysed these scans.

HsCRP is one of the acute phase proteins. The hs CRP values were based on particle enhanced turbidometric immunoassay (PETIA) technique. A synthetic particle coated with antibody to $C$ reactive protein (CRP) aggregates in the presence of CRP in the sample. The increase in turbidity which accompanies aggregation is proportional to the concentration of CRP. Blood was drawn with minimally traumatic venepuncture for measurement of hsCRP, centrifuged at 3000rpm at four ${ }^{\circ} \mathrm{C}$ for 15 minutes, and aliquots were stored at - $700 \mathrm{C}$. Circulating hsCRP was measured by PETIA technique with a sensitivity of $0.5 \mathrm{mg} / \mathrm{dL}$,

Evaluation of cardiovascular risk factors hypertension was defined by casual blood pressure $2140 / 90 \mathrm{~mm} \mathrm{Hg}$ or by current anti-hypertensive therapy. Joint National Committee VII criteria explained this. [12].

Statistical analysis: The data was tabulated in excel spaced sheet, expressed as rates, ratios and percentages. Fischer exact test was used to find the statistical significance; $\mathrm{P}<0.05$ was considered statistically significant.

\section{Results}

Total $51(100 \%)$ members were included in this research; $51 \%$ (26) were male participants, and the male-female ratio was 1.04 . SBI was presented in $27.4 \%$ (14). Among this, $21.5 \%$ (11) had subcortical infarcts and $4(7.8 \%)$ and cortical infarcts and 1 had both infarcts. Age-wise, among the cortical SBI patients, maximum (75\%) were in $\geq 61$ years group. At the same time, it was $31-45$ years group $(36 \% ; 4)$ in subcortical followed by 46 $-60(27 \% ; 3)$ years (Table 1$)$.

Table 1: Age wise distribution of study participants with SBI; n (\%)

\begin{tabular}{|l|l|l|}
\hline \multicolumn{1}{|c|}{ Age } & \multicolumn{1}{|c|}{ Cortical } & \multicolumn{1}{c|}{ Subcortical } \\
\hline $18-30$ & $1(25)$ & $2(18)$ \\
\hline
\end{tabular}

\begin{tabular}{|l|l|l|}
\hline $31-45$ & 0 & $4(36)$ \\
\hline $46-60$ & 0 & $3(27)$ \\
\hline$>61$ & $3(75)$ & $2(18)$ \\
\hline Total & $4(100)$ & $11(100)$ \\
\hline
\end{tabular}

In cortical SBI patients, the maximum was in $\geq 61$ years, and it was $31-45$ group in subcortical.

High density lipoprotein (HDL) levels were $>40$ $\mathrm{mg} / \mathrm{dL}$ in $39.2 \%$ (20) and in the remaining, it was < $40 \mathrm{mg} / \mathrm{dL}$. Normal triglycerides were observed in $71 \%$ (36) participants and raised hsCRP was observed in $62.7 \%$ (32).

Table 2: TGL levels among the participants with SBI; n (\%)

\begin{tabular}{|l|l|l|}
\hline \multicolumn{1}{|c|}{ TGL in $\mathrm{mg} / \mathrm{dL}$} & \multicolumn{1}{c|}{ Cortical } & \multicolumn{1}{c|}{ Subcortical } \\
\hline$<150$ & $2(50)$ & $6(55)$ \\
\hline$>150$ & $2(50)$ & $5(45)$ \\
\hline Total & $4(100)$ & $11(100)$ \\
\hline Statistical analysis & $\mathrm{P}=0.662 ;$ no statistical significance \\
\hline
\end{tabular}

There was no statistical significance in HDL levels among the cortical and subcortical patients.

Among the cortical SBI participants, TGL levels were 2 each in < $150 \mathrm{mg} / \mathrm{dL}$ and > $150 \mathrm{mg} / \mathrm{dL}$. Whereas it was 6 and 5 respectively among the subcortical SBI participants; statistically, there was no significant difference (Table 2). hsCRP levels were raised in $3(75 \%)$ members with cortical SBI and 8 (73\%) participants with subcortical SBI; statistically, there was no significant difference (Table 3).

Table 3: hsCRP levels among the participants with SBI; n (\%)

\begin{tabular}{|l|l|l|}
\hline \multicolumn{1}{|c|}{ hsCRP in $\mathbf{~ m g / d L}$} & \multicolumn{1}{c|}{ Cortical } & \multicolumn{1}{c|}{ Sub cortical } \\
\hline$<3$ & $1(25)$ & $3(27)$ \\
\hline$>3$ & $3(75)$ & $8(73)$ \\
\hline Total & $4(100)$ & $11(100)$ \\
\hline Statistical analysis & $\mathrm{P}=0.725 ;$ no statistical significance \\
\hline
\end{tabular}

There was no statistical significance in hs-CRP levels among the cortical and subcortical patients.

Among the cortical SBI, 75\% had mini mental scale examination (MMSE) scores $<30$. At the same time, it was just $27.7 \%$ among the subcortical SBI members. In both, maximum members had max body index (BMI) 19.5 to 24.99. HDL levels were $<40 \mathrm{mg} / \mathrm{dL}$ in $75 \%$ (3) and 55\% (6), respectively, in cortical and subcortical SBI members.

\section{Discussion}

SBI is usually detected in MRI, first described by Fisher. [13]. 
As per the recent studies, the prevalence was reported to be $10.7 \%$. [1]. Age, gender, DM, atrial fibrillation, hypertension, carotid artery disease and smoking are the reported risk factors of SBI. [14]. Risk factors that are modified behavioural changes include smoking, alcohol, diet and exercise to reduce obesity, waist-hip ratio and stress reduction. [15]. Most of the patients with nonspecific neurological complications presented with a history of neurological symptoms such as headache, vertigo, giddiness, transient motor disturbances, transient sensory disturbances and transient loss of memory. A study found that raised hsCRP, which is the asymptomatic marker of inflammation, is associated with more prevalent and incident lacunar infarcts. [16]. So in this study, we studied the clinical profile, risk factors and association of hsCRP, TGL with SBI. In this study, 51 patients have included; 26 males (50.98\%) and 25 females (49.02\%). In a study done by Van Dijk et al. [16]. Women had a higher risk of marked subcortical WHL incidents than SBI's compared to men. In another report, the incidence of SBI was reported to be $26.1 \%$ and $15.2 \%$, respectively, among the male and female. Whereas in this study, the gender difference is almost 1 . Patients presented with NSCL were higher in the 31 - 45 years $(16 ; 31.37 \%$ ) followed by 46 - 60 years $(10 ; 19.6 \%)$ and 9 $(17.6 \%)$ in $\geq 61$ years. Among the patients presenting with nonspecific neurological complaints, most of the patients were above 30 years. Das et al. reported that SBI is more common among individuals with $>61$ years. [1]. The overall prevalence of SBI in the study group was $27.45 \%$, which was $16 \%$ in the literature. [17]. Helsinki University investigators studied 1008 consecutive patients aged 15 - 49 years; they reported that SBI usually reflecting small vessel disease were detected in $20 \%$ healthy elders and up to $50 \%$ in suspected series having a stroke as risk factors. They also found that SBI is common in patients less than 45 years. [18]. The overall prevalence rates were similar when compared to other studies. In this study, among NSCL, 31 (60.78\%) had abnormal $\mathrm{HDL}$, and the rest $(20 ; 39.22 \%)$ had average $\mathrm{HDL}$ level. In a study by Kato T et al. $[19,20]$. We were reported that there is no significant association between normal HDL levels and silent brain infarcts. This finding was consistent with our results in the study. In this study, a group of patients presenting with NSCL a total of $29.4 \%$ (15) patients presented with raised TGL levels and the rest $(36 ; 70.59 \%$ ) had normal triglyceride.
In the study group of patients presenting with nonspecific neurological complaints, had increased hsCRP levels was observed in $32(62.75 \%)$, and the rest had normal hsCRP levels. In the study group, cortical SBI were detected in $50 \%$ of patients (2) with raised triglyceride (TGL) levels, and $45.45 \%$ (5) had raised TGL in the subcortical SBI group. In the available literature, $[7,11]$. It was reported that independent of risk factors such as elevated blood pressure, impaired fasting glucose, hypertriglyceridaemia, and waist circumference were significant risk factors for SBIs. Kato $\mathrm{T}$ et al. [19]. reported that there was a significant association between raised TGL and low HDL with SBIs, and similar findings were reported by another western study also [21]. This result was consistent with the findings of our research. In this report, a higher incidence of SBI was detected in hypertensive members; similar findings were reported by Das et al. [1]. As such, reasons were not mentioned for this. But the defect in the blood flow could be the significant cause for this.

\section{Conclusion}

The traditional risk factors associated with stroke were present in the patients with SBI. His CRP was raised in CKD patients having NSCL and SBI; however, there was no statistically significant association between them.

\section{What this study adds to the existing knowledge}

Hs CRP was raised in CKD patients having NSCL and having SBI

Limitations: small sample size and lack of follow up are the limitations of this research.

\section{Author's contribution}

P Sasanka: Complete idea of the study, sample collection and study proceedings, article writing. $\mathbf{T}$ Jaya Chandra: Article writing, data analysis.

\section{Reference}

01. Das RR, Seshadri S, Beiser AS, Kelly-Hayes M, Au R, Himali JJ, Kase CS, et al. prevalence and correlates of silent cerebral infarcts in the Framingham offspring study. Stroke. 2008 Nov;39(11):2929-35. doi: 10.1161/STROKEAHA. 108.516575 [Crossref]

[PubMed][Google Scholar] 
02. Eguchi K, Kario K, Shimada K. Greater impact of coexistence of hypertension and diabetes on silent cerebral infarcts. Stroke. 2003 Oct;34(10):2471-4. doi: $\quad$ 10.1161/01.STR.0000089684.41902.CD [Crossref][PubMed][Google Scholar]

03. Hougaku $\mathrm{H}$, Matsumoto M, Kitagawa K, Harada $\mathrm{K}$, Oku N, Itoh T, et al. Silent cerebral infarction as a form of hypertensive target organ damage in the brain. Hypertension. 1992 Dec;20(6):816-20. doi: 10.1161/01.hyp.20.6.816 [Crossref][PubMed] [Google Scholar]

04. Putaala J, Kurkinen M, Tarvos V, Salonen O, Kaste $M$, Tatlisumak T. Silent brain infarcts and leukoaraiosis in young adults with first-ever ischemic stroke. Neurology. 2009 May 26;72(21):1823-9. doi: 10.1212/WNL.0b013e3181a711df [Crossref] [PubMed][Google Scholar]

05. Vermeer SE, Longstreth WT Jr, Koudstaal PJ. Silent brain infarcts: a systematic review. Lancet Neurol. 2007 Jul;6(7):611-9. doi: 10.1016/S14744422(07)70170-9 [Crossref][PubMed][Google Scholar]

06. Wersching $H$, Duning $T$, Lohmann $H$, Mohammadi S, Stehling $C$, Fobker $M$, et al. Serum $C$-reactive protein is linked to cerebral microstructural integrity and cognitive function. Neurology. 2010 Mar 30;74(13):1022-9. doi: 10.1212/WNL.0b013e3181d7b45b [Crossref] [PubMed][Google Scholar]

07. Hoshi T, Kitagawa K, Yamagami H, Furukado S, Hougaku H, Hori M. Relations of serum highsensitivity C-reactive protein and interleukin-6 levels with silent brain infarction. Stroke. 2005 Apr;36(4):768-72. doi: 10.1161/01.STR.00001589 15.28329.51 [Crossref][PubMed][Google Scholar]

08. Fornage M, Chiang YA, O'Meara ES, Psaty BM, Reiner AP, Siscovick DS, et al. Biomarkers of Inflammation and MRI-Defined Small Vessel Disease of the Brain: The Cardiovascular Health Study. Stroke. 2008 Jul;39(7):1952-9. doi: 10.1161/STROKEAHA.107.508135 [Crossref] [PubMed][Google Scholar]

09. Nakane H, Ibayashi S, Fujii K, Sadoshima S, Irie $\mathrm{K}$, Kitazono T, Fujishima M. Cerebral blood flow and metabolism in patients with silent brain infarction: occult misery perfusion in the cerebral cortex. J Neurol Neurosurg Psychiatry. 1998 Sep;65(3):31721. doi: 10.1136/jnnp.65.3.317 [Crossref][PubMed] [Google Scholar]
10. Prabhakaran S, Wright $C B$, Yoshita M, Delapaz R, Brown T, DeCarli C, Sacco RL. Prevalence and determinants of subclinical brain infarction: the Northern Manhattan Study. Neurology. 2008 Feb $5 ; 70(6): 425-30$. doi: 10.1212/01.wnl.0000277521.66947.e5 [Crossref] [PubMed][Google Scholar]

11. Park K, Yasuda N, Toyonaga S, Tsubosaki E, Nakabayashi H, Shimizu K. Significant associations of metabolic syndrome and its components with silent lacunar infarction in middle aged subjects. J Neurol Neurosurg Psychiatry. 2008 Jun;79(6):71921. doi: 10.1136/jnnp.2007.134809 [Crossref] [PubMed][Google Scholar]

12. Chiu YH, Wu SC, Tseng CD, Yen MF, Chen TH. Progression of pre-hypertension, stage 1 and 2 hypertension (JNC 7): a population-based study in Keelung, Taiwan (Keelung Community-based Integrated Screening No 9). J Hypertens. 2006 May;24(5):821-8. doi: 10.1097/01.hjh.0000222750.82820.19 [Crossref] [PubMed][Google Scholar]

13. Fisher $\mathrm{Cm}$. Lacunes: Small, deep cerebral Infarcts. Neurology. 1965 Aug;15:774-84. doi: 10.1212/wnl.15.8.774 [Crossref][PubMed][Google Scholar]

14. Masuda J, Nabika T, Notsu Y. Silent stroke: pathogenesis, genetic factors and clinical implications as a risk factor. Curr Opin Neurol. 2001 Feb;14(1):77-82. doi: 10.1097/00019052200102000-00012 [Crossref][PubMed][Google Scholar]

15. Sacco, Ralph L, et al. "Guidelines for prevention of stroke in patients with ischemic stroke or transient ischemic attack: a statement for healthcare professionals from the American Heart Association/American Stroke Association Council on Stroke: co-sponsored by the Council on Cardiovascular Radiology and Intervention: the American Academy of Neurology affirms the value of this guideline". Stroke. 37;2(2006):577-617. [Crossref][PubMed][Google Scholar]

16. Van Dijk EJ, Prins ND, Vermeer SE, Vrooman HA, Hofman A, Koudstaal PJ, Breteler MM. Creactive protein and cerebral small-vessel disease: the Rotterdam Scan Study. Circulation. 2005 Aug 9;112(6):900-5. doi: 10.1161/CIRCULATIONAHA.104.506337 [Crossref] [PubMed][Google Scholar] 
17. Willey JZ, Moon YP, Paik MC, Yoshita M, Decarli C, Sacco RL, Elkind MS, Wright CB. Lower prevalence of silent brain infarcts in the physically active: the Northern Manhattan Study. Neurology. 2011 Jun 14;76(24):2112-8. doi: 10.1212/WNL.0b013e31821f4472 [Crossref] [PubMed][Google Scholar]

18. Putaala J, Metso AJ, Metso TM, Konkola N, Kraemer Y, Haapaniemi $E$, et al. analysis of 1008 consecutive patients aged 15 to 49 with first-ever ischemic stroke: the Helsinki young stroke registry. Stroke. 2009 Apr;40(4):1195-203. doi: 10.1161/STROKEAHA.108.529883 [Crossref] [PubMed][Google Scholar]

19. Kato $\mathrm{T}$, Inoue $\mathrm{T}$, Yamagishi $\mathrm{S}$, Morooka $\mathrm{T}$, Okimoto T, Node K. Low-density lipoprotein subfractions and the prevalence of silent lacunar infarction in subjects with essential hypertension. Hypertens Res. 2006 May;29(5):303-7. doi: 10.1291/hypres.29.303 [Crossref][PubMed][Google Scholar]
20. Uehara T, Tabuchi M, Mori E. Risk factors for silent cerebral infarcts in subcortical white matter and basal ganglia. Stroke. 1999 Feb;30(2):378-82. doi: 10.1161/01.str.30.2.378 [Crossref][PubMed] [Google Scholar]

21. Norrving B. Lacunar infarcts: no black holes in the brain are benign. Pract Neurol. 2008 Aug;8(4):222-8. doi: 10.1136/jnnp.2008.153601 [Crossref][PubMed][Google Scholar]

22. Alberti KG, Zimmet PZ. Definition, diagnosis and classification of diabetes mellitus and its complications, Part 1: diagnosis and classification of diabetes mellitus provisional report of a WHO consultation. Diabet Med. 1998 Jul;15(7):539-53. doi: $\quad 10.1002 /(S I C I) 1096-$ 9136(199807)15:7<539::AID-DIA668>3.0.CO;2-S [Crossref][PubMed][Google Scholar] 